\title{
Diffuse large B cell lymphoma: molecular targeted therapy
}

\author{
Mark Roschewski • Kieron Dunleavy • \\ Wyndham H. Wilson
}

Received: 5 September 2012/Revised: 28 September 2012/Accepted: 30 September 2012/Published online: 20 October 2012

(C) The Japanese Society of Hematology (outside the USA) 2012

\begin{abstract}
Diffuse large B cell lymphoma (DLBCL) is a biologically heterogeneous disease and the most common subtype of B cell non-Hodgkin's lymphoma in the USA. Even though it is a curable lymphoma in advanced stages, up to $40 \%$ of patients eventually relapse or fail to achieve remission. Improved understanding of the biologic complexity of DLBCL reveals a diverse range of oncogenic driver mutations and signaling pathways that are essential for growth and survival of malignant cells. Since many of these signaling pathways can be targeted by small-molecule inhibitors, the therapy for DLBCL is currently undergoing a paradigm shift away from conventional chemotherapy and toward targeted agents that capitalize on an improved biologic understanding of the subsets with the highest risk of treatment failure. Participation in wellconducted and rationally designed clinical trials will be essential to realize the potential of these targeted agents and realize the goal of improving overall outcomes in the most common B cell lymphoma in the world.
\end{abstract}

Keywords Diffuse large B cell lymphoma - DLBCL . $\mathrm{NF}-\kappa \mathrm{B} \cdot \mathrm{STAT} 3 \cdot \mathrm{BCR}$ signaling

\footnotetext{
M. Roschewski ( $\square) \cdot$ K. Dunleavy · W. H. Wilson Lymphoma Therapeutics Section, Metabolism Branch, National Cancer Institute, NIH, 9000 Rockville Pike, Bethesda, MD 20892, USA

e-mail: roschewskimj@mail.nih.gov

K. Dunleavy

e-mail: dunleavk@mail.nih.gov

W. H. Wilson

e-mail: wilsonw@mail.nih.gov
}

\section{Introduction: current standard of care for DLBCL}

Diffuse large B cell lymphoma (DLBCL) is the most common subtype of B cell non-Hodgkin lymphoma (NHL), representing approximately $30-40 \%$ of the estimated 70,130 cases of NHL in the USA in 2012 and is curable in the majority of cases [1]. Still, 30-40\% of patients eventually relapse or fail to achieve remission, and it is estimated that nearly 19,000 people will die of DLBCL in 2012 in the USA [1]. Given this incidence, even modest improvements in the outcomes of DLBCL patients have the potential for tremendous impact, making novel drug development in this disease a priority.

Since it was first recognized that DLBCL could be cured with combination chemotherapy in the 1970s [2], the search for an optimal regimen has been ongoing. Anthracyclines have established themselves as the most effective drug class and a variety of combination regimens exist [3-5]. First-generation combination regimens using cyclophosphamide, doxorubicin, vincristine, and prednisone (CHOP) were first studied extensively in national cooperative settings, and a landmark randomized trial in 1993 established CHOP as the gold standard over other chemotherapy regimens that relied on higher dose intensity [3]. The alternative regimens resulted in more toxicity without resultant improvements in outcomes [3]. However, the pharmacodynamically derived infusional regimen of dose-adjusted (DA) EPOCH utilizes the addition of etoposide and is highly effective for DLBCL, including highly proliferative variants [5].

It has been the development of rituximab, a monoclonal antibody targeted against CD20, however, that has made the single greatest impact on the treatment of DLBCL since $\mathrm{CHOP}$ was first introduced. The first study to demonstrate the benefit of rituximab in advanced DLBCL was a 
randomized study of $\mathrm{CHOP}$ or $\mathrm{CHOP}$ with rituximab (R-CHOP) in patients over 60 years old [6]. In this study, the complete remission (CR) rate (76 vs. $63 \%)$ and 5-year event-free survival (EFS) (47 vs. $29 \%$ ) were higher with $\mathrm{R}-\mathrm{CHOP}$ than $\mathrm{CHOP}$, and this survival advantage remains at 10 years follow-up [6, 7]. The MabThera International Trial (MInT) also demonstrated a survival benefit of rituximab when added to CHOP-based treatment in patients $\leq 60$ years with low IPI risk [8], making immunochemotherapy regimens such as R-CHOP the "de facto" standard in DLBCL. These early successes in remission rates and event-free survival have recently been confirmed to result in durable improvements in overall survival, including patients over age 80 years, and without unanticipated longterm toxicities [7-10]. Rituximab can also be safely added to DA-EPOCH therapy with improvements in survival compared to historical controls [11, 12], and this regimen (DA-EPOCH-R) is currently being compared to R-CHOP in newly diagnosed DLBCL in a phase III randomized trial. Importantly, rituximab benefits all subgroups of DLBCL and likely overcomes historical methods of resistance in the pre-rituximab era such as overexpression of Bcl-2 [13]. Thus, modern immunochemotherapy regimens induce complete remissions in $80-85 \%$ of patients with newly diagnosed DLBCL, and future successes that rival the revolutionary effect seen with rituximab will need to exploit emerging insights into the oncogenic pathways that drive disease in the $15-20 \%$ of patients who are at the highest risk for treatment failure with R-CHOP or DA-EPOCH-R.

\section{Risk stratification of DLBCL}

Diffuse large B cell lymphoma is a widely heterogeneous disease associated with numerous genetic alterations and characterized by underlying biologic diversity. The most widely used prognostic tool prior to therapy is the International Prognostic Index (IPI) [14] which separates patients into categories with differential prognosis, but does not capture biologic specificity. Multiple new tools are available which have illustrated that specific molecular subgroups of DLBCL are at highest risk for treatment failure with R-CHOP and have identified potential therapeutic targets. Ideally, elucidation of driver mutations and biologic processes that are responsible for treatment resistance will lead to targeted strategies based on this biologic diversity between subgroups.

Gene expression profiling (GEP) of DLBCL has demonstrated significant molecular heterogeneity within morphologically indistinguishable tumors [15]. DLBCL can be divided into three different subtypes: germinal center B cell (GCB) type, activated B cell ( $\mathrm{ABC}$ ) type and primary mediastinal B cell lymphoma (PMBL) type that arise by distinct pathogenetic mechanisms and have a very different prognosis [16-19]. PMBL patients have the best prognosis and recently it has been demonstrated that the majority of them can be cured with an effective regimen without radiation therapy [20]. Patients with GCB-type DLBCL have a better prognosis than ABC-type DLBCL when treated with R-CHOP [21], and this discordance in outcomes was also seen in patients treated with DA-EPOCH-R therapy in which the 5-year progression-free survival (PFS) was $100 \%$ for the GCB type compared to $67 \%$ for the $\mathrm{ABC}$ type [12]. The majority of patients who fail initial therapy, therefore, are likely to be of the $\mathrm{ABC}$ type and identifying therapeutic targets in this group are of high priority.

The pathogenic hallmark of ABC-type DLBCL is the constitutive activation of the nuclear factor- $\kappa \mathrm{B}(\mathrm{NF}-\kappa \mathrm{B})$ pathway through a variety of mechanisms, which promotes cell proliferation and protection from apoptosis [22]. The NF- $\kappa \mathrm{B}$ family of proteins is a group of five transcription factors (RelA, RelB, c-Rel, NF- $\kappa \mathrm{B} 1$, and NF- $\kappa \mathrm{B} 2$ ) that are typically kept inactive by inhibitory cytoplasmic proteins [23]. Three proteins, CARD11, BCL10, and MALT1, form a signaling complex (CBM) which leads to the activation of NF- $\kappa \mathrm{B}$ following antigen stimulation of the $\mathrm{B}$ cell receptor (BCR) [24] (Fig. 1). The classical NF- $\kappa$ B pathway is engaged in ABC-type DLBCL through chronic active BCR signaling in over $20 \%$ of cases, but not commonly found in other lymphoma subtypes [24]. Mutations in CARD11 are found in up to $10 \%$ of cases of ABC-type DLBCL, but not in the GCB type [25]. An alternative pathway of NF- $\kappa$ B activation through aberrant activation

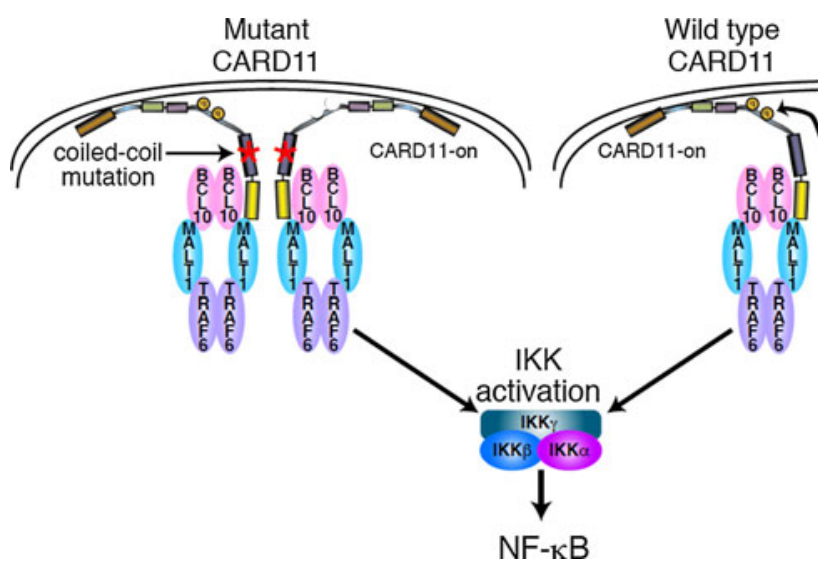

Fig. 1 The CARD11, BCL10, MALT1 (CBM) complex, and mechanisms of NF- $\kappa \mathrm{B}$ activation in ABC-like DLBCL. Activating mutations of the coiled domain of CARD11 occur in $10 \%$ of cases of ABC-like DLBCL that lead to constitutive activation of the NF- $\kappa \mathrm{B}$ pathway, while cases of wild-type CARD11 are associated with chronic active $\mathrm{B}$ cell receptor (BCR) signaling. Treatment may depend on the mechanism by which NF- $\kappa \mathrm{B}$ is activated. Figure courtesy of Lou Staudt and adapted from [95] 
of innate immune system signaling is stimulation of the toll-like receptor (TLR) pathway via bacterial lipopolysaccharides. Adaptor proteins important for the signaling of TLR pathway, such as MYD88, are commonly mutated in ABC-like DLBCL. Point mutations at the leucine residue position 265 (L265P) of MYD88 can be found in $30 \%$ of cases of ABC-type DLBCL, but rarely in GCB-like DLBCL [26]. Importantly, other signaling pathways such as the Janus-activating kinase (JAK)/signal transducer and activator of transcription (STAT) pathway cooperate with $\mathrm{NF}-\kappa \mathrm{B}$ to provide growth signals and are also promoted by MYD88. ABC cell lines and tumor specimens have high levels of the STAT3 protein representing another potential therapeutic target [27-29]. A third mechanism of NF- $\kappa \mathrm{B}$ activation is the deletion of the negative regular A20 which is found in up to $30 \%$ of cases of ABC-type DLBCL [30].

Approximately, $10 \%$ of newly diagnosed DLBCL patients harbor an underlying translocation of the $M Y C$ oncogene on chromosome 8 as a secondary genetic event in association with a complex karyotype [31]. Molecularly, these lymphomas utilize fundamentally distinct pathogenetic mechanisms from Burkitt lymphoma (BL) [32]. Most cases involve the immunoglobulin heavy chain gene on chromosome 14, but light chain genes on chromosome 2 (kappa) and 22 (lambda) are also seen. A subset of these cases also harbor an underlying translocation at the second breakpoint such as BCL2, BCL6, or cyclin D1 [33, 34]. These lymphomas, commonly present with poor prognostic features such as extranodal disease and high IPI, and carry a dismal prognosis $[35,36]$. Patients with $\mathrm{MYC}^{+}$DLBCL and "double-hit" or "triple-hit" lymphomas are at high risk for treatment failure with R-CHOP and warrant special consideration. More recently, the identification of c-myc protein via immunohistochemical methods on formalinfixed paraffin-embedded tissue has been described [37], and cases of DLBCL which are positive for both BCL2 and c-myc protein also have a poor prognosis [38, 39]. Importantly, the bio-CORAL study recently reported that patients with MYC translocation (17\% of all patients) did not benefit from ASCT in the relapsed setting [40], further highlighting the need for novel approaches in this subset.

\section{NF- $\kappa$ B pathway inhibition}

The NF- $\kappa \mathrm{B}$ pathway of transcription factors is responsible for the control of multiple cellular processes, many of which are the hallmarks of cancer cells. These processes include cytokine secretion, inflammation, proliferation, angiogenesis, invasion, and metastasis. It is not surprising, then, that $\mathrm{NF}-\kappa \mathrm{B}$ is frequently deregulated in DLBCL and that many tumor cells are addicted to $\mathrm{NF}-\kappa \mathrm{B}$ - especially ABC-like DLBCL. Activation of $\mathrm{NF}-\kappa \mathrm{B}$ follows two pathways: the canonical (classic) and the non-canonical (alternative), both of which are regulated by inhibitory proteins known as $\mathrm{I} \kappa \mathrm{B}$ proteins, which are, in turn, regulated by the IKK complex (IKK $\alpha, \operatorname{IKK} \beta$, and $\operatorname{IKK} \gamma)$. Constitutive activation of the $\mathrm{NF}-\kappa \mathrm{B}$ pathway is required for the survival of ABC-like DLBCL, and the genetic ablation of key NF- $\kappa \mathrm{B}$ signaling molecules results in B cell differentiation arrest and prevents activation [23]. The validation of $\mathrm{NF}-\kappa \mathrm{B}$ pathway as a promising therapeutic target was first demonstrated when small-molecule inhibitors of the IKK complex such as I $\kappa \mathrm{B}$ kinase (IKK) demonstrated selective inhibition of $\mathrm{ABC}$-like cell lines in vitro [41]. Multiple agents that target the NF- $\kappa \mathrm{B}$ pathway through a variety of mechanisms have demonstrated selective efficacy in patients with ABC-like DLBCL.

Proteasome is a multiprotein complex with three proteolytic activities associated with distinct subunits: the peptidylglutamyl-like ( $\beta 1$-subunit), trypsin-like ( $\beta 2$-subunit), and the chymotrypsin-like ( $\beta 5$-subunit). Bortezomib is a dipeptidyl boronic acid derivative and the first in the class of proteasome inhibitors that reversibly target the chymotrypsin-like activity of the proteasome and has demonstrated activity in lymphoma [42, 43]. Bortezomib blocks the degradation of phosphorylated $\mathrm{I} \kappa \mathrm{B} \alpha$, subsequently downregulating the NF- $\kappa \mathrm{B}$ pathway [44, 45]. The activity of bortezomib in ABC-like DBLCL was first demonstrated in a landmark study by Dunleavy et al., who treated 49 patients with relapsed and refractory DLBCL with DA-EPOCH with bortezomib. ABC-like DLBCL patients had an $83 \%$ response rate, while the response rate for GCB-like DLBCL was only $13 \%$ with a survival advantage in the ABC-like patients of 10.8 months compared to 3.4 months [46]. Similarly, Ruan et al. treated 40 patients with untreated DLBCL with R-CHOP in combination with escalating doses of bortezomib and demonstrated an overall response rate of $100 \%$ with complete remission rate of $86 \%$ and manageable toxicities [47]. Importantly, this study found similar survival outcomes at 2 years with GCB-like and ABC-like DLBCL. Taken together, these findings have prompted multi-institutional studies including a randomized phase II study of R-CHOP with and without bortezomib [NCT: 00931918] in untreated ABC-like DLBCL and a nonrandomized assessment of R-ICE with bortezomib [NCT: 01226849] in relapsed/refractory ABC-like DLBCL to better understand the impact of bortezomib on this subset.

Lenalidomide is an oral immunomodulatory agent, approved for use in multiple myeloma, which exerts impressive anti-cancer effects through multiple mechanisms that include inhibition of angiogenesis, recruitment of natural killer cells, upregulation of costimulatory molecules such as CD80 and CD40, impairment of inflammatory cytokine production, and effects on adhesion in the tumor microenvironment $[45,48]$. In one phase II study evaluating 
lenalidomide as a single agent in 26 patients with relapsed/ refractory aggressive B cell lymphoma, remissions were observed in $20 \%$ of patients with DLBCL with duration of response of over 6 months. Importantly, selectivity for the ABC-like subset of DLBCL by lenalidomide has been observed. In one study, a $55 \%$ response rate in patients with relapsed ABC-like DLBCL was observed compared to only $9 \%$ in patients with relapsed GCB-like DLBCL [49]. In an effort to understand the mechanism of action in $\mathrm{ABC}$ like DLBCL, Yang et al. [50] exposed both ABC-like and GCB-like cell lines to lenalidomide in vitro. They demonstrated that lenalidomide selectively killed ABC-like cells by augmenting interferon $\beta$ (IFN $\beta$ ) production. Specifically, lenalidomide inhibits NF- $\kappa$ B by downregulating the transcription factors interferon regulatory factor 4 (IRF4) and SPIB, which are characteristically expressed in ABC-like DLBCL and usually serve to prevent IFN $\beta$ production [50]. Signatures of NF- $\kappa$ B, MYD88, and JAK were downregulated by lenalidomide suggesting that the TLR pathway was inhibited. This toxic effect of lenalidomide on ABC-like cells also was dependent on the expression of cereblon, an observation also seen in the antimyeloma activity of lenalidomide [51]. Most importantly, additional inhibition of IKK with either the selective inhibitor MLN120B or the Bruton's tyrosine kinase (Btk) inhibitor, ibrutinib, led to undetectable IRF4 expression. A combination of lenalidomide and ibrutinib also proved highly effective in arresting the growth of ABC-like tumors in mouse models suggesting a highly active combination regimen [50].

Another strategy to inhibit the NF- $\kappa$ B pathway is the prevention of polyubiquination of $\mathrm{I} \kappa \mathrm{B} \alpha$, a process that marks it for degradation via the proteasome. Since this process requires neddylation, the inhibition of the NEDD8activating enzyme (NAE) would serve to stabilize $\mathrm{I} \kappa \mathrm{B} \alpha$ with the overall result being NF- $\kappa$ B inhibition. MLN4924 is a selective small-molecule inhibitor of NAE that demonstrates significant activity against a variety of cancer cell lines and mouse xenograft models to include ABC-like DLBCL [52, 53]. Importantly, the tumoricidal effects of MLN4924 were specific for ABC-like DLBCL in vivo and were not observed in GCB-like DLBCL, further supporting the notion of selective inhibitors based on specific molecular background. Studies for testing MLN4924 in combination with chemotherapy in relapsed ABC-like DLBCL have been planned [NCT: 01415765].

\section{B cell receptor signaling inhibition}

The survival of normal B cells requires continuous signaling (tonic) through the surface BCR, which thereby engages downstream growth and survival pathways such as phosphoinositide 3-kinase (PI3K), protein kinase $\mathrm{C}$ $(\mathrm{PKC} \beta)$, and mammalian target of rapamycin (mTOR). BCR signaling is mediated through a variety of protein tyrosine kinases such as spleen tyrosine kinase (SYK), Lyn, and BTK [54] (Fig. 2). In ABC-like DLBCL, signaling via the BCR pathway is independent of antigen stimulation and results from mutations in the BCR such as CARD11, MYD88, and CD79A/B that engage the classical NF- $\kappa$ B pathway. This chronic active BCR signaling renders ABC-like DLBCL cells "addicted" to the pathway and susceptible to its inhibition. Many of these tyrosine kinases critical for BCR signaling and amplification are amenable
Fig. 2 B cell receptor (BCR) signaling pathway. One mechanism of NF- $\kappa \mathrm{B}$ activation is chronic active BCR signaling found in $30 \%$ of patients with ABC-like DLBCL. Protein kinases essential for this signaling represent upstream targets subject to smallmolecule inhibition with agents that target SYK (fostamatinib), BTK (ibrutinib), PI3K $\delta$ (GS 1101), and PKC (enzastaurin). Figure courtesy of Adrian Wiestner and adapted from [96]

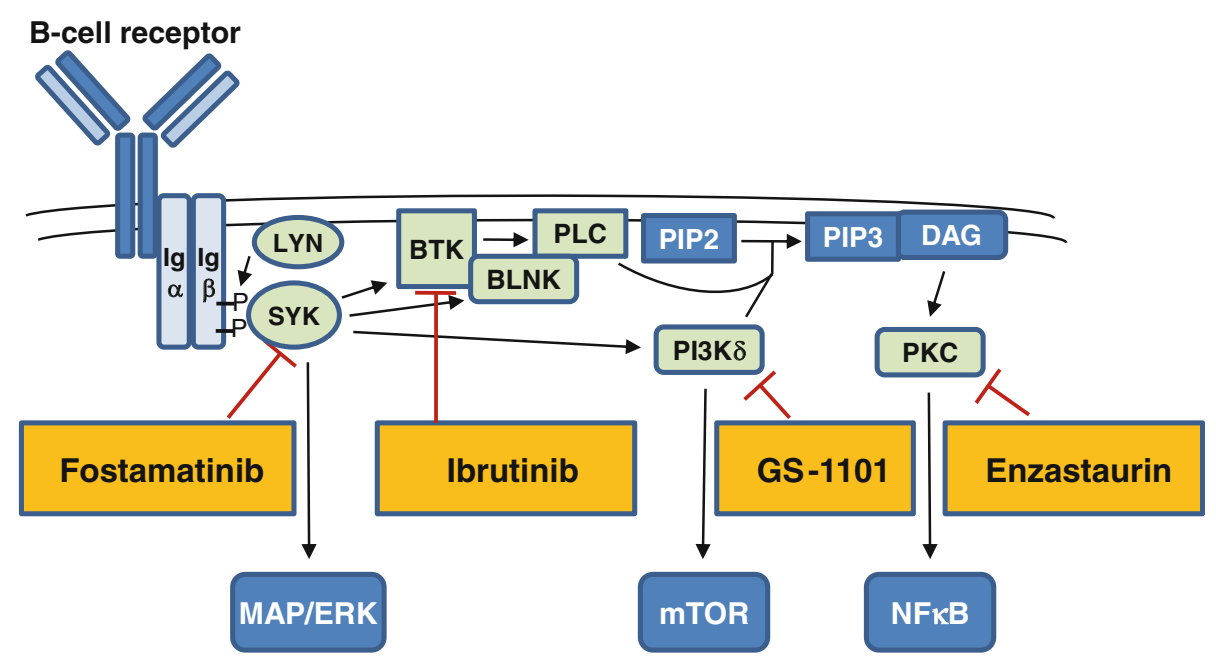


to inhibition by small molecules. Among the most promising agents in DLBCL (and other B cell malignancies) are these small-molecule inhibitors that interrupt upstream processes involved in BCR signaling and the downstream pathways that are responsible for cellular proliferation.

SYK is a protein tyrosine kinase with close proximity to $\mathrm{BCR}$ that is responsible for amplification of the BCR signal and activation of downstream events such as PI3K and Akt [54]. Inhibition of SYK in subsets of DLBCL cell lines induced significant apoptosis leading to its clinical development [55]. In a phase $1 / 2$ study of an oral inhibitor of SYK, fostamatinib, 23 patients with relapsed DLBCL were treated and a modest overall response rate of $22 \%$ was observed with one complete remission and a PFS of 2.7 months [56]. Fostamatinib was well tolerated with dose-limiting toxicities, predominantly hematologic in nature, in addition to diarrhea. Even though the single agent activity of fostamatinib was modest in DLBCL, it was one of the first in vivo demonstrations of the potential of BCR pathway inhibition.

Btk is a tyrosine kinase that is activated early in the BCR signaling cascade. Ibrutinib (formerly PCI-32765) is an oral small molecule that selectively and irreversibly inhibits Btk through binding with cysteine-481 [57]. In dogs with spontaneous B cell lymphoma, ibrutinib induced objective clinical responses prompting its clinical development in B cell malignancies [58]. In a phase 1 trial testing ibrutinib in a variety of relapsed/refractory B cell malignancies, no dose-limiting toxicity was determined and the overall response rate was $60 \%$ [59]. Two short hairpin RNAs, specifically target to Btk, demonstrated toxicity for wild-type CARD11 ABC DLBCL subtype with no effect on cell lines with CARD11 mutations suggesting that ibrutinib selectively kills those which rely on constitutive BCR signaling [24]. Preliminary results from a phase II study of ibrutinib in relapsed/refractory DLBCL [NCT01325701] revealed that 2 of the first 8 patients treated with ibrutinib at $560 \mathrm{mg}$ daily underwent complete remission for 11 and 5 months, respectively [60]. In addition, one patient who was primarily refractory to chemotherapy had stable disease and was successfully bridged to allogeneic transplantation. Pre-treatment and post-treatment biopsies on 5 patients were analyzed by GEP and suggested that cytotoxic T cells and macrophages were decreased in patients with clinical response, but not in those without, suggesting that the underlying mechanism of interruption of BCR signaling involved cytokine modulation. Indeed, Btk is a promising target in ABC DLBCL, and future combination studies with conventional chemotherapy are planned.

$\operatorname{PKC} \beta$ is a serine/threonine kinase that is amplified through the BCR activation pathway and responsible for growth and survival of $\mathrm{B}$ cells via the BCR, NF- $\kappa \mathrm{B}$ and
VEGF pathways. GEP identified PKC $\beta$ as an unfavorable prognostic marker in DLBCL [61], and in vitro evidence involving DLBCL cell lines suggested that $\mathrm{PKC} \beta$ represented a rational therapeutic target in DLBCL [62]. Enzastaurin is a potent oral inhibitor of $\mathrm{PKC} \beta$ that has been studied in relapsed/refractory DLBCL [63], as well as in combination with $\mathrm{R}-\mathrm{CHOP}$ in patients with intermediate and high-risk DLBCL [64]. In a phase II study, 55 patients with relapsed/refractory DLBCL were treated with once daily enzastaurin on a continuous daily basis [63]. Four patients $(7 \%)$ experienced significant freedom from progression over 20 months and 3 patients had a complete remission and the overall toxicities were manageable. The preliminary analysis has been reported of a randomized phase II study of patients with high- or intermediate-risk DLBCL given either enzastaurin with R-CHOP for 6 cycles versus R-CHOP alone [64]. After 100 patients had been enrolled, the experimental group treated with enzastaurin demonstrated a 1-year PFS of $71 \%$ compared to only $52 \%$ of those without enzastaurin with similar toxicity profiles. The results of this trial will determine the feasibility and effectiveness of this approach moving forward.

The family of PI3K kinases is another example of protein kinases with a central role in BCR signaling that are amenable to inhibition by small molecules. GS 1101 (formerly CAL 101) is a potent small-molecule inhibitor of PI3K $\mathrm{p} 110 \delta$ that blocks constitutive PI3K signaling in vitro [65]. In a phase I study, GS 1101 was studied in 9 patients with DLBCL and was well tolerated, but did not result in clinical responses [66]. It is being developed in indolent NHL and may eventually prove to have a role in the management of DLBCL.

\section{STAT3 signaling inhibition}

Another important oncogenic signaling pathway that cooperates with NF- $\kappa \mathrm{B}$ to promote survival of $\mathrm{ABC}$-like DLBCL and represents a possible therapeutic target is the Janus activated kinase (JAK)/STAT signaling pathway. STAT3 expression and activation are significantly higher in ABC cell lines than GCB cell lines and likely play a role in the chemoresistance of this subset [27, 28]. The STAT proteins are a family of transcription factors important for the regulation of cellular event such as proliferation and survival [67]. The constitutive activation of the NF- $\kappa$ B pathway in ABC DLBCL induces the secretion of IL- 6 and IL-10, which promotes survival through the activation of the JAK family of kinases (JAK1, JAK2, JAK3, and TYK2) [68]. The JAK family of kinases phosphorylate the transcription of STAT proteins, which dimerize and relocate to the nucleus where they activate target genes important for cellular proliferation [69]. A gene expression 
signature demonstrate that about half of ABC DLBCLs show elevated activity of STAT3 activity (STAT3-high) and have higher NF- $\kappa$ B activity than those with low STAT3 activity (STAT3-low), as well as increased expression of proliferation genes [28]. Importantly, selective inhibition of STAT3 signaling resulted in dosedependent cellular death in ABC, but not GCB cell lines [28]. Additionally, when JAK inhibitors were combined with selective inhibitors of $\operatorname{IKK} \beta$, synergistic killing was observed [28]. In mouse models, direct inhibition of STAT3 with short hairpin RNA (shRNA) suppresses the growth of ABC-like DLBCL in concert with STAT3 downregulation, further validating its possible anti-tumor effects in lymphoma [29]. In addition to evidence of direct cytotoxicity to tumor cells, the targeting of STAT3 may also activate intrinsic anti-tumor immune mechanisms by effects on dendritic cells, $\mathrm{T}$ cells, and natural killer cells [70].

Direct therapeutic targeting of STAT3 signaling is difficult since it lacks its own enzymatic activity. Thus, the most advanced method for targeting STAT3 signaling to date is to use small molecules that target the JAK family of tyrosine kinases such as SB1518 [71] and ruxolitinib [72]. Ruxolitinib is an oral selective inhibitor of JAK1 and JAK2 that has gained FDA approval in the USA for the treatment of primary myelofibrosis (PMF) and related conditions in November of 2011 [73, 74]. In a phase $1 / 2$ study of myelofibrosis patients, ruxolitinib proved to be well tolerated with dose-limiting side effects related to reversible effects on the hematopoietic system such as anemia and thrombocytopenia [74]. A dose-dependent suppression of STAT3 expression was demonstrated in this study that was independent of the presences of JAK mutations. Given the strong pre-clinical evidence that inhibition of JAK/STAT signaling is lethal to ABC DLBCL, an ongoing multicenter phase II study of ruxolitinib in relapsed/refractory DLBCL is currently ongoing [NCT: 01431209].

Another potential method of inhibiting IL-6 induced JAK/STAT signaling involves the targeting of proteins that co-localize with STAT3 such as sphingosine-1-phosphate receptor 1 (S1PR1) that are involved in the regulation of STAT3 signaling [75]. S1PR1 is a G protein-coupled receptor that is elevated in STAT3 positive tumors; enhanced S1PR1 expression can activate STAT3 through JAK2 upregulation, thereby accelerating tumor growth and metastasis [75]. In ABC cell lines in mouse models, the inhibition of S1PR1 via shRNA as well as an antagonist of S1P downregulated STAT3 activity and induced growth arrest and apoptosis. These findings suggest targeting S1PR1 may be another method by which the STAT signaling pathway could be clinically targeted [76]. Similarly, histone deacetylase (HDAC) proteins can regulate co-localizing proteins such as STAT3 through reversible site-specific protein acetylation [77]. HDAC3, which is a class I HDAC, is overexpressed in STAT3-positive DBLCL and can be specifically targeted with agents such as panobinostat (LBH589) [78]. In ABC cell lines, HDAC3 was found to be overexpressed compared to GCB cell lines and they were more sensitive to the effects of HDAC inhibition with LBH [78]. Panobinostat is currently being tested in a multi-institutional phase II study in relapsed/ refractory DLBCL and other NHLs [NCT: 01261247]. Indeed, the STAT signaling pathway is a viable therapeutic target and a variety of agents have been under exploration to determine their clinical efficacy.

\section{BCL6 inhibition}

Although the ABC-like subset of DLBCL has a poorer prognosis than GCB-like DLBCL, cases of relapsed or refractory DLBCL are not exclusively $\mathrm{ABC}$-like and the development of targeted agents based on the biology of the GCB-like subset is also necessary. The GCB subtype of DLBCL typically expresses genes normally found in the germinal center of normal B cells, such as CD10 and LMO2 $[15,16]$. A common molecular abnormality is the deregulation of the $b c l-6$ gene, which is a key transcriptional regulator of the germinal center reaction [79]. BCL6 protein functions as a transcription factor that binds a specific DNA sequence and represses the transcription of genes involved in critical biologic processes, such as cell cycle regulation, DNA damage response, and apoptosis $[80,81]$. BCL6 is required for germinal center cell formation during antigen-driven immune response [82]. Thus, DLBCLs with high expression of BCL6 on immunohistochemistry are usually of GCB origin, and this may distinguish them from other DLBCL subtypes [83]. Similar to STAT proteins, since BCL6 is a transcriptional factor, it is difficult to target directly and is best affected by targeting protein-protein interactions. Recently, a small molecule was identified that specifically disrupted the activity of BCL6 by blocking its corepressors [84]. The compound, known as 79-6 complex, was able to selectively induce apoptosis in DLBCL cell lines that were BCL6 dependent, but not those that were BCL6 independent. In a xenograft model in mice, 79-6 was able to induce tumor shrinkage validating BCL6 inhibition as a rational therapeutic strategy for DLBCL tumors that overexpress BCL6 [84].

\section{MYC-positive subsets of DLBCL}

In contradistinction to the good prognosis of patients with BL, DLBCL patients who harbor a translocation of the MYC oncogene have a poor prognosis [85, 86]. DLBCL 
with an additional translocation, such as $B C L 2$ or $B C L 6$, are dubbed "double-hit lymphomas" (DHL) and have an especially grave prognosis $[33,34]$. Although the underlying signaling pathways that confer resistance in patients with $\mathrm{MYC}^{+}$DLBCL or DHL are not well characterized, these patients do poorly when treated with R-CHOP and do not benefit much from salvage chemotherapy and ASCT upon relapse [40]. Early indications suggest that DA-EPOCH-R may overcome the resistance conferred by MYC positivity, but further follow-up is necessary [87]. The Myc oncoproteins (c-Myc, N-Myc, and L-Myc) have generally been considered "undruggable" targets, because the protein structures are not amenable to small-molecule inhibition. However, recent epigenetic manipulation of the BET bromodomain protein BRD4 by the compound JQ1 has demonstrated exciting promise in inhibiting c-Myc in murine models of multiple myeloma [88, 89], since bromodomain proteins serve as regulatory factors for c-Myc and can potentially alter gene expression. Another mechanism by which Myc promotes lymphomagenesis is by suppressing the transcription of tristetrapolin (TTP), which functions as a tumor suppressor [90]. Normal gene expression is tightly controlled by mRNA turnover which is, in turn, tightly regulated by AU-binding proteins (AUBP) that recognize AU-rich elements (ARE) within transcripts. TTP is an example of an AUBP that is suppressed in cancers with Myc involvement, and restoring TTP impairs Myc-induced lymphomagenesis and abolishes the malignant state [90]. Both of these strategies represent novel epigenetic targeting of $\mathrm{MYC}^{+}$tumors that could potentially be combined with chemotherapy.

\section{Aurora kinase inhibition}

Another potential therapeutic target with exciting promise in DLBCL is the inhibition of Aurora kinase A, also known as serine/threonine-protein kinase 6 (STK6). Aurora kinases $\mathrm{A}$ and $\mathrm{B}$ are mitotic kinases responsible for checkpoint regulation of the mammalian cell cycle and mitotic initiation. Aurora A is overexpressed in DLBCL as compared to normal B cells [91] and is linked to chemotherapy resistance to important agents with antilymphoma activity such as vinca alkaloids and other microtubule-targeting agents [92]. Aurora A is subject to therapeutic targeting by smallmolecule inhibitors such as MLN8237 (alisertib), an oral agent which selectively inhibits Aurora kinase A activity. MLN8237 induces apoptosis in aggressive B cell lymphoma cell lines; in a multicenter phase 1 study of MLN8237 as a single agent in advanced hematologic malignancies including DLBCL, mild antitumor activity was observed with manageable toxicities [93]. The principal toxicities of MLN8237 are related to myelosuppression and, importantly, it has demonstrated synergy when combined with both vincristine and rituximab both in vitro and in xenograft models [94]. Since both vincristine and rituximab are without significant effects on normal hematopoeisis, the combination of MLN8237 with both of them (MVR) is being tested in a multicenter phase 1-2 trial of relapsed DLBCL [NCT: 01397825].

\section{Conclusions}

Diffuse large B cell lymphoma is best understood as a heterogeneous disease with multiple subsets that are driven by a diverse range of oncogenic mutations and signaling pathways. As a result, the therapy for DLBCL is currently undergoing a paradigm shift away from conventional chemotherapy and toward targeted agents that capitalize on an improved biologic understanding of the subsets with the highest risk of treatment failure. Other agents not mentioned in this paper include those that also exhibit promise, including new monoclonal antibodies against CD20 and CD22 as well as the mTOR inhibitor, everolimus. However, a full discussion is beyond the scope of this review. In the rituximab era, the majority of patients with DLBCL who relapse after initial therapy will be represented by high-risk subsets such as $\mathrm{MYC}^{+}$, "double-hit" lymphomas, transformed lymphomas, and the ABC-like subtype. High-dose therapy with autologous stem cell transplantation is likely to have a diminished role, as targeted agents increase their role in the relapsed setting and, eventually, in the initial management of these curable lymphomas. Participation in wellconducted and rationally designed clinical trials will be essential to realize the potential of these targeted agents and realize the goal of improving overall outcomes in the most common B cell lymphoma in the world.

Acknowledgments All research support came from the Intramural Research Program of the NIH.

Conflict of interest No conflicts of interest to declare.

\section{References}

1. Siegel R, Naishadham D, Jemal A. Cancer statistics, 2012. CA. Cancer J Clin. 2012;62(1):10-29.

2. DeVita VT, Jr., Canellos GP, Chabner B, Schein P, Hubbard SP, Young RC. Advanced diffuse histiocytic lymphoma, a potentially curable disease. Lancet. 1975;1(7901):248-50.

3. Fisher RI, Gaynor ER, Dahlberg S, Oken MM, Grogan TM, Mize $\mathrm{EM}$, et al. Comparison of a standard regimen (CHOP) with three intensive chemotherapy regimens for advanced non-Hodgkin's lymphoma. N Engl J Med. 1993;328(14):1002-6.

4. Pfreundschuh M, Trumper L, Kloess M, Schmits R, Feller AC, Rudolph C, et al. Two-weekly or 3-weekly CHOP chemotherapy 
with or without etoposide for the treatment of young patients with good-prognosis (normal LDH) aggressive lymphomas: results of the NHL-B1 trial of the DSHNHL. Blood. 2004;104(3):626-33.

5. Wilson WH, Grossbard ML, Pittaluga S, Cole D, Pearson D, Drbohlav N, et al. Dose-adjusted EPOCH chemotherapy for untreated large B cell lymphomas: a pharmacodynamic approach with high efficacy. Blood. 2002;99(8):2685-93.

6. Coiffier B, Lepage E, Briere J, Herbrecht R, Tilly H, Bouabdallah $\mathrm{R}$, et al. CHOP chemotherapy plus rituximab compared with CHOP alone in elderly patients with diffuse large-B cell lymphoma. N Engl J Med. 2002;346(4):235-42.

7. Coiffier B, Thieblemont C, Van Den Neste E, Lepeu G, Plantier I, Castaigne $\mathrm{S}$, et al. Long-term outcome of patients in the LNH98.5 trial, the first randomized study comparing rituximab-CHOP to standard CHOP chemotherapy in DLBCL patients: a study by the Groupe d'Etudes des Lymphomes de l'Adulte. Blood. 2010; 116(12):2040-5.

8. Pfreundschuh M, Trumper L, Osterborg A, Pettengell R, Trneny $\mathrm{M}$, Imrie $\mathrm{K}$, et al. CHOP-like chemotherapy plus rituximab versus CHOP-like chemotherapy alone in young patients with good-prognosis diffuse large-B cell lymphoma: a randomised controlled trial by the MabThera International Trial (MInT) Group. Lancet Oncol. 2006;7(5):379-91.

9. Pfreundschuh M, Kuhnt E, Trumper L, Osterborg A, Trneny M, Shepherd L, et al. CHOP-like chemotherapy with or without rituximab in young patients with good-prognosis diffuse large-B cell lymphoma: 6-year results of an open-label randomised study of the MabThera International Trial (MInT) Group. Lancet Oncol. 2011;12(11):1013-22.

10. Lee L, Crump M, Khor S, Hoch JS, Luo J, Bremner K, et al. Impact of rituximab on treatment outcomes of patients with diffuse large B cell lymphoma: a population-based analysis. Br J Haematol. 2012;158(4):481-8.

11. Wilson WH, Dunleavy K, Pittaluga S, Hegde U, Grant N, Steinberg SM, et al. Phase II study of dose-adjusted EPOCH and rituximab in untreated diffuse large $\mathrm{B}$ cell lymphoma with analysis of germinal center and post-germinal center biomarkers. J Clin Oncol. 2008;26(16):2717-24.

12. Wilson WH, Jung SH, Porcu P, Hurd D, Johnson J, Martin SE, et al. A Cancer and Leukemia Group B multi-center study of DA-EPOCH-rituximab in untreated diffuse large B cell lymphoma with analysis of outcome by molecular subtype. Haematologica. 2011;97(5):758-65.

13. Fu K, Weisenburger DD, Choi WWL, Perry KD, Smith LM, Shi $\mathrm{X}$, et al. Addition of rituximab to standard chemotherapy improves the survival of both the germinal center B cell-like and non-germinal center B cell-like subtypes of diffuse large B cell lymphoma. J Clin Oncol. 2008;26(28):4587-94.

14. A predictive model for aggressive non-Hodgkin's lymphoma. The International Non-Hodgkin's Lymphoma Prognostic Factors project. N Engl J Med. 1993;329(14):987-94.

15. Alizadeh AA, Eisen MB, Davis RE, Ma C, Lossos IS, Rosenwald A, et al. Distinct types of diffuse large B cell lymphoma identified by gene expression profiling. Nature. 2000; 403(6769):503-11.

16. Rosenwald A, Wright G, Chan WC, Connors JM, Campo E, Fisher RI, et al. The use of molecular profiling to predict survival after chemotherapy for diffuse large-B cell lymphoma. N Engl J Med. 2002;346(25):1937-47.

17. Rosenwald A, Wright G, Leroy K, Yu X, Gaulard P, Gascoyne $\mathrm{RD}$, et al. Molecular diagnosis of primary mediastinal B cell lymphoma identifies a clinically favorable subgroup of diffuse large B cell lymphoma related to Hodgkin lymphoma. J Exp Med. 2003;198(6):851-62.

18. Wright G, Tan B, Rosenwald A, Hurt EH, Wiestner A, Staudt LM. A gene expression-based method to diagnose clinically distinct subgroups of diffuse large B cell lymphoma. Proc Natl Acad Sci USA. 2003;100(17):9991-6.

19. Lenz G, Wright GW, Emre NCT, Kohlhammer H, Dave SS, Davis RE, et al. Molecular subtypes of diffuse large B cell lymphoma arise by distinct genetic pathways. Proc Nat Acad Sci. 2008;105(36):13520-5.

20. Dunleavy K, Pittaluga S, Shovlin M, Grant N, Grant C, Chen C, et al. Untreated primary mediastinal B cell (PMBL) and mediastinal grey zone (MGZL) lymphomas: comparison of biological features and clinical outcome following DA-EPOCH-R without radiation. Annals Oncol. 2011;22 (supplement 4):(Abstract 150).

21. Lenz G, Wright G, Dave SS, Xiao W, Powell J, Zhao H, et al. Stromal gene signatures in large-B cell lymphomas. N Engl J Med. 2008;359(22):2313-23.

22. Davis RE, Brown KD, Siebenlist U, Staudt LM. Constitutive nuclear factor kappaB activity is required for survival of activated B cell-like diffuse large B cell lymphoma cells. J Exp Med. 2001;194(12): 1861-74.

23. Lim KH, Yang Y, Staudt LM. Pathogenetic importance and therapeutic implications of NF-kappaB in lymphoid malignancies. Immunol Rev. 2012;246(1):359-78.

24. Davis RE, Ngo VN, Lenz G, Tolar P, Young RM, Romesser PB, et al. Chronic active B cell-receptor signalling in diffuse large B cell lymphoma. Nature. 2010;463(7277):88-92.

25. Lenz G, Davis RE, Ngo VN, Lam L, George TC, Wright GW, et al. Oncogenic CARD11 mutations in human diffuse large B cell lymphoma. Science. 2008;319(5870):1676-9.

26. Ngo VN, Young RM, Schmitz R, Jhavar S, Xiao W, Lim KH, et al. Oncogenically active MYD88 mutations in human lymphoma. Nature. 2011;470(7332):115-9.

27. Ding BB, Yu JJ, Yu RY, Mendez LM, Shaknovich R, Zhang Y, et al. Constitutively activated STAT3 promotes cell proliferation and survival in the activated B cell subtype of diffuse large B cell lymphomas. Blood. 2008;111(3):1515-23.

28. Lam LT, Wright G, Davis RE, Lenz G, Farinha P, Dang L, et al. Cooperative signaling through the signal transducer and activator of transcription 3 and nuclear factor-\{kappa\}B pathways in subtypes of diffuse large B cell lymphoma. Blood. 2008;111(7): 3701-13.

29. Scuto A, Kujawski M, Kowolik C, Krymskaya L, Wang L, Weiss LM, et al. STAT3 inhibition is a therapeutic strategy for ABClike diffuse large B cell lymphoma. Cancer Res. 2011;71(9): 3182-8.

30. Kato M, Sanada M, Kato I, Sato Y, Takita J, Takeuchi K, et al. Frequent inactivation of A20 in B cell lymphomas. Nature. 2009;459(7247):712-6.

31. Jaffe ES, Pittaluga S. Aggressive B cell lymphomas: a review of new and old entities in the WHO classification. Hematol Am Soc Hematol Educ Program. 2011;2011:506-14.

32. Schmitz R, Young RM, Ceribelli M, Jhavar S, Xiao W, Zhang M, et al. Burkitt lymphoma pathogenesis and therapeutic targets from structural and functional genomics. Nature. 2012.

33. Snuderl M, Kolman OK, Chen YB, Hsu JJ, Ackerman AM, Dal Cin P, et al. B cell lymphomas with concurrent IGH-BCL2 and MYC rearrangements are aggressive neoplasms with clinical and pathologic features distinct from Burkitt lymphoma and diffuse large B cell lymphoma. Am J Surg Pathol. 2010;34(3):327-40.

34. Aukema SM, Siebert R, Schuuring E, van Imhoff GW, KluinNelemans HC, Boerma EJ, et al. Double-hit B cell lymphomas. Blood. 2011;117(8):2319-31.

35. Johnson NA, Savage KJ, Ludkovski O, Ben-Neriah S, Woods R, Steidl C, et al. Lymphomas with concurrent BCL2 and MYC translocations: the critical factors associated with survival. Blood. 2009;114(11):2273-9.

36. Tomita N. BCL2 and MYC dual-hit lymphoma/leukemia. J Clin Exp Hematop. 2011;51(1):7-12. 
37. Ruzinova MB, Caron T, Rodig SJ. Altered subcellular localization of c-Myc protein identifies aggressive B cell lymphomas harboring a c-MYC translocation. Am J Surg Pathol. 2010;34(6): 882-91.

38. Green TM, Young KH, Visco C, Xu-Monette ZY, Orazi A, Go $\mathrm{RS}$, et al. Immunohistochemical double-hit score is a strong predictor of outcome in patients with diffuse large B cell lymphoma treated with rituximab plus cyclophosphamide, doxorubicin, vincristine, and prednisone. J Clin Oncol. 2012;30(28): 3460-7.

39. Johnson NA, Slack GW, Savage KJ, Connors JM, Ben-Neriah S, Rogic S, et al. Concurrent Expression of MYC and BCL2 in Diffuse Large B Cell Lymphoma Treated With Rituximab Plus Cyclophosphamide, Doxorubicin, Vincristine, and Prednisone. J Clin Oncol. 2012;30(28):3452-9.

40. Cuccuini W, Briere J, Mounier N, Voelker HU, Rosenwald A, Sundstrom C, et al. $\mathrm{MYC}^{+}$diffuse large B-cell lymphoma is not salvaged by classical R-ICE or R-DHAP followed by BEAM plus autologous stem cell transplantation. Blood. 2012;119(20): 4619-24.

41. Lam LT, Davis RE, Pierce J, Hepperle M, Xu Y, Hottelet M, et al. Small molecule inhibitors of IkappaB kinase are selectively toxic for subgroups of diffuse large B cell lymphoma defined by gene expression profiling. Clin Cancer Res. 2005;11(1):28-40.

42. Goy A, Phase II. Study of proteasome inhibitor bortezomib in relapsed or refractory B cell non-Hodgkin's lymphoma. J Clin Oncol. 2005;23(4):667-75.

43. Fisher RI, Bernstein SH, Kahl BS, Djulbegovic B, Robertson MJ, de Vos S, et al. Multicenter phase II study of bortezomib in patients with relapsed or refractory mantle cell lymphoma. J Clin Oncol. 2006;24(30):4867-74.

44. Strauss SJ, Higginbottom K, Juliger S, Maharaj L, Allen P, Schenkein D, et al. The proteasome inhibitor bortezomib acts independently of p53 and induces cell death via apoptosis and mitotic catastrophe in B cell lymphoma cell lines. Cancer Res. 2007;67(6):2783-90.

45. Mahadevan D, Fisher RI. Novel therapeutics for aggressive nonHodgkin's lymphoma. J Clin Oncol. 2011;29(14):1876-84.

46. Dunleavy K, Pittaluga S, Czuczman MS, Dave SS, Wright G, Grant N, et al. Differential efficacy of bortezomib plus chemotherapy within molecular subtypes of diffuse large B cell lymphoma. Blood. 2009;113(24):6069-76.

47. Ruan J, Martin P, Furman RR, Lee SM, Cheung K, Vose JM, et al. Bortezomib plus CHOP-rituximab for previously untreated diffuse large B cell lymphoma and mantle cell lymphoma. J Clin Oncol. 2011;29(6):690-7.

48. Chanan-Khan AA, Cheson BD. Lenalidomide for the treatment of B cell malignancies. J Clin Oncol. 2008;26(9):1544-52.

49. Hernandez-Ilizaliturri FJ, Deeb G, Zinzani PL, Pileri SA, Malik F, Macon WR, et al. Higher response to lenalidomide in relapsed/ refractory diffuse large $\mathrm{B}$ cell lymphoma in nongerminal center $\mathrm{B}$ cell-like than in germinal center B cell-like phenotype. Cancer. 2011;117(22):5058-66.

50. Yang Y, Shaffer AL 3rd, Emre NC, Ceribelli M, Zhang M, Wright G, et al. Exploiting synthetic lethality for the therapy of ABC diffuse large B cell lymphoma. Cancer Cell. 2012;21(6): 723-37.

51. Zhu YX, Braggio E, Shi CX, Bruins LA, Schmidt JE, Van Wier S, et al. Cereblon expression is required for the antimyeloma activity of lenalidomide and pomalidomide. Blood. 2011;118(18):4771-9.

52. Soucy TA, Smith PG, Milhollen MA, Berger AJ, Gavin JM, Adhikari S, et al. An inhibitor of NEDD8-activating enzyme as a new approach to treat cancer. Nature. 2009;458(7239):732-6.

53. Milhollen MA, Traore T, Adams-Duffy J, Thomas MP, Berger AJ, Dang L, et al. MLN4924, a NEDD8-activating enzyme inhibitor, is active in diffuse large B cell lymphoma models: rationale for treatment of NF-\{kappa $\} \mathrm{B}$-dependent lymphoma. Blood. 2010;116(9):1515-23.

54. Gauld SB. Dal Porto JM, Cambier JC. B cell antigen receptor signaling: roles in cell development and disease. Science. 2002;296(5573):1641-2.

55. Chen L, Monti S, Juszczynski P, Daley J, Chen W, Witzig TE, et al. SYK-dependent tonic B cell receptor signaling is a rational treatment target in diffuse large B cell lymphoma. Blood. 2008;111(4):2230-7.

56. Friedberg JW, Sharman J, Sweetenham J, Johnston PB, Vose JM, Lacasce A, et al. Inhibition of Syk with fostamatinib disodium has significant clinical activity in non-Hodgkin lymphoma and chronic lymphocytic leukemia. Blood. 2010;115(13):2578-85.

57. Winer ES, Ingham RR, Castillo JJ. PCI-32765: a novel Bruton's tyrosine kinase inhibitor for the treatment of lymphoid malignancies. Expert Opin Investig Drugs. 2012;21(3):355-61.

58. Honigberg LA, Smith AM, Sirisawad M, Verner E, Loury D, Chang B, et al. The Bruton tyrosine kinase inhibitor PCI-32765 blocks B cell activation and is efficacious in models of autoimmune disease and B cell malignancy. Proc Natl Acad Sci USA. 2010;107(29):13075-80.

59. Kenkre VP, Kahl BS. The future of B cell lymphoma therapy: the B cell receptor and its downstream pathways. Curr Hematol Malig Rep. 2012;7(3):216-20.

60. Staudt LM, Dunleavy K, Buggy JJ, Hedrick E, Lucas N, Pittaluga S, et al. The Bruton's Tyrosine Kinase (Btk) Inhibitor PCI-32765 Modulates Chronic Active BCR Signaling and Induces Tumor Regression in Relapsed/Refractory ABC DLBCL. ASH Annual Meeting Abstracts. 2011;118(21):2716.

61. Shipp MA, Ross KN, Tamayo P, Weng AP, Kutok JL, Aguiar $\mathrm{RC}$, et al. Diffuse large B cell lymphoma outcome prediction by gene-expression profiling and supervised machine learning. Nat Med. 2002;8(1):68-74.

62. Rossi RM, Henn AD, Conkling R, Guzman ML, Bushnell T, Harvey $\mathbf{J}$, et al. The $\operatorname{PKC} \beta$ selective inhibitor, enzastaurin (LY317615), inhibits growth of human lymphoma cells. ASH Annual Meeting Abstracts. 2005;106(11):1483.

63. Robertson MJ, Kahl BS, Vose JM, de Vos S, Laughlin M, Flynn $\mathrm{PJ}$, et al. Phase II study of enzastaurin, a protein kinase $\mathrm{C}$ beta inhibitor, in patients with relapsed or refractory diffuse large B cell lymphoma. J Clin Oncol. 2007;25(13):1741-6.

64. Hainsworth JD, Arrowsmith ER, Mccleod M, Fayad LE, Hamid $\mathrm{O}$, Davis L, et al. Randomized phase II study of R-CHOP plus enzastaurin versus R-CHOP in the first line treatment of patients with intermediate and high-risk diffuse large B cell lymphoma (DLBCL) - preliminary analysis. Annals Oncol. 2011;22(suppl 4):(Abstract 074).

65. Lannutti BJ, Meadows SA, Herman SEM, Kashishian A, Steiner B, Johnson AJ, et al. CAL-101, a p110 selective phosphatidylinositol-3-kinase inhibitor for the treatment of B cell malignancies, inhibits PI3K signaling and cellular viability. Blood. 2010;117(2):591-4.

66. Furman RR, Byrd JC, Brown JR, Coutre SE, Benson DM, Jr., Wagner-Johnston ND, et al. CAL-101, an isoform-selective inhibitor of phosphatidylinositol 3-kinase P110D, demonstrates clinical activity and pharmacodynamic effects in patients with relapsed or refractory chronic lymphocytic leukemia. ASH Annual Meeting Abstracts. 2010;116(21):55.

67. Calo V, Migliavacca M, Bazan V, Macaluso M, Buscemi M, Gebbia N, et al. STAT proteins: from normal control of cellular events to tumorigenesis. J Cell Physiol. 2003;197(2):157-68.

68. Murray PJ. The JAK-STAT signaling pathway: input and output integration. J Immunol. 2007;178(5):2623-9.

69. Bromberg J, Darnell JE Jr. The role of STATs in transcriptional control and their impact on cellular function. Oncogene. 2000;19(21):2468-73. 
70. Kortylewski M, Kujawski M, Wang T, Wei S, Zhang S, Pilon-Thomas S, et al. Inhibiting Stat3 signaling in the hematopoietic system elicits multicomponent antitumor immunity. Nat Med. 2005;11(12):1314-21.

71. Hart S, Goh KC, Novotny-Diermayr V, Hu CY, Hentze H, Tan $\mathrm{YC}$, et al. SB1518, a novel macrocyclic pyrimidine-based JAK2 inhibitor for the treatment of myeloid and lymphoid malignancies. Leukemia. 2011;25(11):1751-9.

72. Mascarenhas J, Hoffman R. Ruxolitinib: the first FDA approved therapy for the treatment of myelofibrosis. Clin Cancer Res. 2012;18(11):3008-14.

73. Verstovsek S, Mesa RA, Gotlib J, Levy RS, Gupta V, DiPersio $\mathrm{JF}$, et al. A double-blind, placebo-controlled trial of ruxolitinib for myelofibrosis. N Engl J Med. 2012;366(9):799-807.

74. Verstovsek S, Kantarjian H, Mesa RA, Pardanani AD, CortesFranco J, Thomas DA, et al. Safety and efficacy of INCB018424, a JAK1 and JAK2 inhibitor, in myelofibrosis. N Eng1 J Med. 2010;363(12):1117-27.

75. Lee H, Deng J, Kujawski M, Yang C, Liu Y, Herrmann A, et al. STAT3-induced S1PR1 expression is crucial for persistent STAT3 activation in tumors. Nat Med. 2010;16(12):1421-8.

76. Liu Y, Deng J, Wang L, Lee H, Armstrong B, Scuto A, et al. S1PR1 is an effective target to block STAT3 signaling in activated B cell like diffuse large B cell lymphoma. Blood. 2012;120(7):1458-65

77. Klampfer L, Huang J, Swaby LA, Augenlicht L. Requirement of histone deacetylase activity for signaling by STAT1. J Biol Chem. 2004;279(29):30358-68.

78. Gupta M, Han JJ, Stenson M, Wellik L, Witzig TE. Regulation of STAT3 by histone deacetylase-3 in diffuse large B cell lymphoma: implications for therapy. Leukemia. 2011;26(6):1356-64.

79. Dent AL, Shaffer AL, Yu X, Allman D, Staudt LM. Control of inflammation, cytokine expression, and germinal center formation by BCL-6. Science. 1997;276(5312):589-92.

80. Polo JM, Dell'Oso T, Ranuncolo SM, Cerchietti L, Beck D, Da Silva GF, et al. Specific peptide interference reveals BCL6 transcriptional and oncogenic mechanisms in B cell lymphoma cells. Nat Med. 2004;10(12):1329-35.

81. Phan RT, Dalla-Favera R. The BCL6 proto-oncogene suppresses p53 expression in germinal-centre B cells. Nature. 2004; 432(7017):635-9.

82. Pasqualucci L, Migliazza A, Fracchiolla N, William C, Neri A, Baldini L, et al. BCL-6 mutations in normal germinal center B cells: evidence of somatic hypermutation acting outside Ig loci. Proc Natl Acad Sci USA. 1998;95(20):11816-21.

83. Colomo L, Lopez-Guillermo A, Perales M, Rives S, Martinez A, Bosch F, et al. Clinical impact of the differentiation profile assessed by immunophenotyping in patients with diffuse large $\mathrm{B}$ cell lymphoma. Blood. 2003;101(1):78-84.
84. Cerchietti LC, Ghetu AF, Zhu X, Da Silva GF, Zhong S, Matthews M, et al. A small-molecule inhibitor of BCL6 kills DLBCL cells in vitro and in vivo. Cancer Cell. 2010;17(4):400-11.

85. Barrans S, Crouch S, Smith A, Turner K, Owen R, Patmore R, et al. Rearrangement of MYC is associated with poor prognosis in patients with diffuse large B cell lymphoma treated in the era of rituximab. J Clin Oncol. 2010;28(20):3360-5.

86. Savage KJ, Johnson NA, Ben-Neriah S, Connors JM, Sehn LH, Farinha $\mathrm{P}$, et al. MYC gene rearrangements are associated with a poor prognosis in diffuse large B cell lymphoma patients treated with R-CHOP chemotherapy. Blood. 2009;114(17):3533-7.

87. Dunleavy K, Pittaluga S, Wayne AS, Shovlin M, Johnson J, Little $\mathrm{R}$, et al. $\mathrm{MYC}^{+}$aggressive B cell lymphomas: novel therapy of untreated Burkitt lymphoma (BL) and $\mathrm{MYC}^{+}$diffuse large $\mathrm{B}$ cell lymphoma (DLBCL) with DA-EPOCH-R. Annals Oncol 2011;22 (suppl 4):(Abstract 071).

88. Delmore JE, Issa GC, Lemieux ME, Rahl PB, Shi J, Jacobs HM, et al. BET bromodomain inhibition as a therapeutic strategy to target c-Myc. Cell. 2011;146(6):904-17.

89. Chesi M, Matthews GM, Garbitt VM, Palmer SE, Shortt J, Lefebure $\mathrm{M}$, et al. Drug response in a genetically engineered mouse model of multiple myeloma is predictive of clinical efficacy. Blood. 2012;120(2):376-85.

90. Rounbehler Robert J, Fallahi M, Yang C, Steeves Meredith A, Li W, Doherty Joanne R, et al. Tristetraprolin impairs myc-induced lymphoma and abolishes the malignant state. Cell. 2012;150(3): 563-74.

91. Hamada M, Yakushijin Y, Ohtsuka M, Kakimoto M, Yasukawa M, Fujita S. Aurora2/BTAK/STK15 is involved in cell cycle checkpoint and cell survival of aggressive non-Hodgkin's lymphoma. Br J Haematol. 2003;121(3):439-47.

92. Anand S, Penrhyn-Lowe S, Venkitaraman AR. AURORA-A amplification overrides the mitotic spindle assembly checkpoint, inducing resistance to Taxol. Cancer Cell. 2003;3(1):51-62.

93. Padmanabhan S, Shea TC, Vose JM, Reeder CB, Berdeja JG, McDonagh KT, et al. Phase I study of an investigational Aurora A kinase inhibitor MLN8237 in patients with advanced hematologic malignancies. ASH Annual Meeting Abstracts. 2010; 116(21):2799.

94. Mahadevan D, Stejskal A, Cooke LS, Manziello A, Morales C, Persky DO, et al. Aurora A inhibitor (MLN8237) plus vincristine plus rituximab is synthetic lethal and a potential curative therapy in aggressive $\mathrm{B}$ cell non-Hodgkin lymphoma. Clin Cancer Res. 2012;18(8):2210-9.

95. Lenz G, Staudt LM. Aggressive lymphomas. N Engl J Med. 2010;362(15):1417-29.

96. Weniger MA, Wiestner A. Molecular targeted approaches in mantle cell lymphoma. Semin Hematol. 2011;48(3):214-26. 